\title{
Study on heredity value in communication skills, for improving individual performance in the workplace
}

\author{
Mihaela Laura Bratu, ${ }^{1, *}$, and Dan Miricescu ${ }^{1}$ \\ ${ }^{1}$ Lucian Blaga University of Sibiu, Emil Cioran Street, No. 4, 550025 Sibiu, Romania
}

\begin{abstract}
Effective communication is the wish of every intelligent organization. In today's society, modern communication means saved time, reduced costs, multiplied resources. Communication can be improved early in the development. Heredity of communication can be an excuse, a brake but also a mean of focus personal resources early in child development. To establish the link between communication and heredity was conducted a study at a nursery school in Sibiu. It have been questioned a number of 98 adults and 45 children, using questionnaires for the evaluation of social and communication skills, attention to detail and distributive, and tolerance to change, carried out by researchers from United Kingdom. Adults who have significant problems of communication, have children with communication problems. The results slightly above average obtained by some adults do not always correlate with slightly different results of the children. Another conclusion is that communication ability has a social and cultural coordinated. The correlations have been established between the responses of children and adults, but cannot identify precisely, slightly above average for the cases, which is the incidence of occurrence of communication problems.
\end{abstract}

\section{Introduction}

In Romania, the so called MTO approach (Man, Technology, Organization) has been one of the main theoretical frameworks for the enhancement of systematic approaches to integrate human, organizational and technological factors in the context of industrial activities [1]. Risk management is carried out by people, acting individually or in groups. The human factor introduces an additional degree of complexity in the risk assessment. Emotional Intelligence provides the means by which attitudes can be managed [2]. The MTO approach brings a lot of advantages from economic and time point of view, but also creates a lack of comunication in tehnological process. So, the human factor can be in the same time very productive, but also „less intelligent” in the emotional way.

Human resource is present within any organization, so occupational health and safety (OHS) is becoming a pillar in sustainable development of the enterprise. Integrating OHS in corporate social responsibility (CSR) leads to an interesting approach that shapes and solves

\footnotetext{
${ }^{*}$ Corresponding author: ybratulaura@gmail.com
} 
a number of current concerns. The integrated approach of the two concepts creates a framework for sustainable work [3]. Organizations, besides the strategic objectives that they have, have also social responsibility for the human resource, to enhance individual compentence, to develop personals skills.

Effective communication is one of the desiderata of any performance, successful organization. Communication quality means success, represents performance, speed of implementation of tasks, represents the optimal use of time and financial, human, material resources [4].

In the labour field are coming individuals with different personality traits and with different communication skills. As a result of the practice, in can be put the following questions: when is the optimal time to develop communication skills, when it can start the personal development of the individual. As earlier is starting, the resistance to change is small and the costs are lower. Advanced societies invest precisely for this reason first of all in the education of children. All it doesn't learn in school period, it will be recovered with costs much higher by employers.

This research has aimed the identification of adults and children with problems of communication and referencing data in order to identify hereditary factor of communicative proficiency.

The present study focuses around four areas that are associated with effective communication: social skills, communication skills, attention to details/distributive attention, tolerance to change [5].

Social skills makes interacting with others easier to. The lack of basic skills such as a smile, greeting, eye contact with the other side, can lead to the inability of the manager to establish a bridge of communication with employees. In the case of complex skills needed to manage conflict, employees can be put in a situation very stressful, because of a lack of social skills. They will be forced to work on the development of social skills consciously.

Communication skills increase processing speed, response time, speed of reaction, leading to understanding and execution tasks as they are envisioned by the superiors. The lack of these skills results in inability to convey accurate information and clear, to relate on horizontal and veritical, to participate in the working meetings to devise improved products etc.

Attention represents a mechanism of orientation and focus of a consciousness on a task, a question, a problem. In its superior forms, attention can be learn, improved, arranged, through the will and thought. There are people who see the smallest details and can track multiple tasks at the same time, but there are employees who are unable to perceive the task as a whole but only certain stages. The manager's role is to know the possibilities of each individual employee and to adapt the communication to the level of attention of the interlocutor.

Changing tolerance means accepting change, adapting to new situations, understanding and changing the behavior according to new parameters. This feature of one's personality is beneficial for employees who work in dynamic environments, constantly changing.

There are employees able to achieve tasks, performance at the required level, but have not developed the capacity for communication, which is a barrier, a barrier in professional development. Often, the performance of the employees are above average, giving evidence of his prodigious intelligence, that becomes an obstacle to communication forms. This type of specific behaviors employees manifest Asperger disorder, specific to gifted persons.

The Autism and Developmental Disabilities Monitoring Network (ADDM) and the Centers for Disease Control and Prevention (CDC) report that in 2002 approximately 10\% of all 8-year-olds in the United States had an Autism Spectrum Disorder (ASD). If these findings are correct, by next year $10 \%$ of all 18 -year-olds in the United States will have an 
Autism Spectrum Disorder [6]. So, in 2017, 10\% of the new hire young people can manifest communication problems.

So, the following questions arise:

1.Employee communication problems have a hereditary component;

2.To what extent can we intervene in childhood to improve the ability of individuals to communicate.

Research conducted at the level of the adults.

The purpose of the questionnaire was to investigate to what extent children who have high scores on applied questionnaires were coming from families with normal adults from the point of view of intelligence, which exhibit autistic-like symptoms.

The questions of the questionnaire covers five areas: social skills, communication skills, imagination, attention to detail, attention to distributive and tolerance change.

The questionnaire includes 50 statements, with four variants of answer: totally agree, partially agree, strongly disagree, totally disagree. Depending on the response, the statement shall be graded with 0 or 1 point, 1 designating the specific behaviors of Asperger syndrome, manifested totally or partial. Each statement describes a typical autistic behavior (asperger's).

People who replied to the questionnaire have been the female gender in $65 \%, 66 \%$ of these having ages between 30 and 40 years.

As a result of questionnaire, $16 \%$ of adults fall into normal spectrum, indicated by questionnaire. However, it cannot be asserted, for reasons such as psychological distress, culture, habits, that the remaining persons have a problem, but only manifests communication difficulties. 3\% of the population has a high score of 37 . Men have higher average scores than women. Immediately above the average of 16 , lies $47 \%$ of women and 76 percent of men. However, there are no men with higher score then 24.

It is considered that with increasing age, people have a greater chance of improving communication, thanks to self-knowledge and social adaptation effort.

Dimension social skills that includes 14 items refer to social interaction, social rules, adapted to the needs of others. Items describe specific behaviors of Asperger syndrome, social expenses, incapable of following social rules, etc.

Social skills vs. Gender

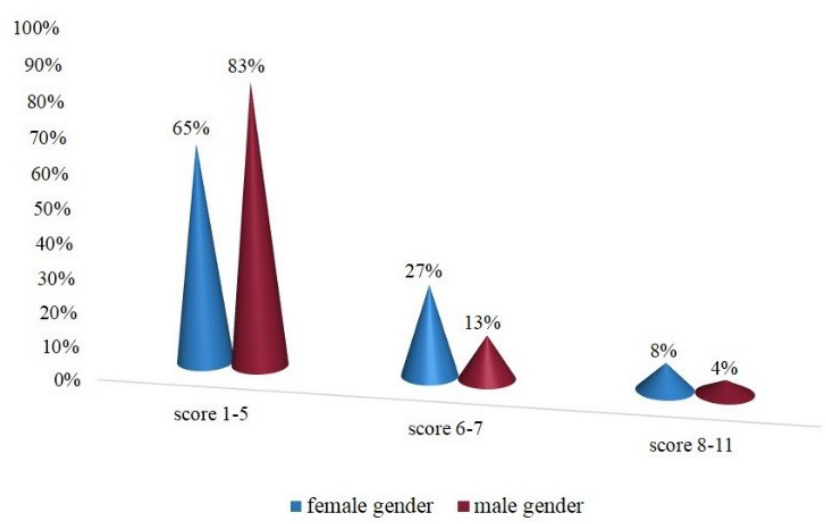

Fig. 1. Social skills vs. Gender

Social skills deficits are at $35 \%$ of women and only $17 \%$ of men.

Communication skills refers to the understanding of game words, verbal stereotypes, nonverbal communication, the interpretation of verbal and nonverbal messages. Within this questionnaire graded deficiencies of this dimension. 


\section{Communication skills vs. Gender}

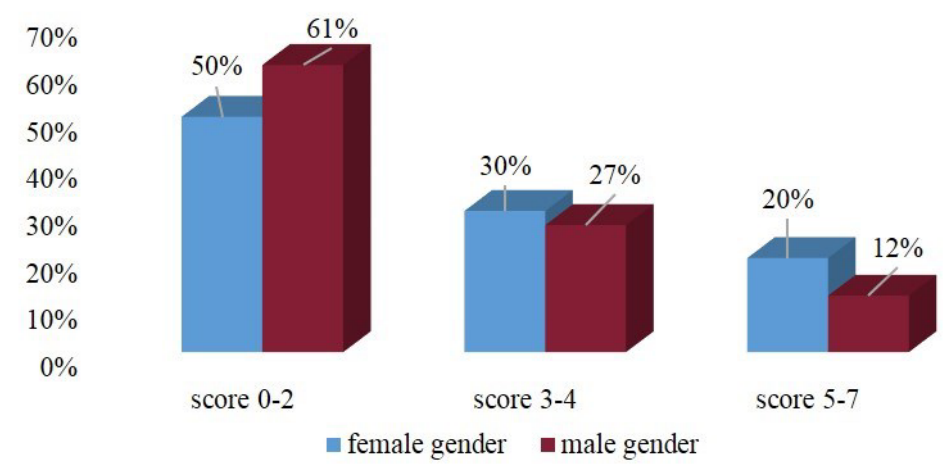

Fig. 2. Communication skills

Analyzing the scores from questionnaires show that women have more communication problems than men, surprising conclusion can be said. Might as a possible cause is the item to which they related, comparing with others female, so is appearing inhibition and low self esteem.

People who are diagnosed with Asperger's Disorder have trouble building mental images, mental visualization and imaging operation constructs.

\section{Imagination vs. Gender}

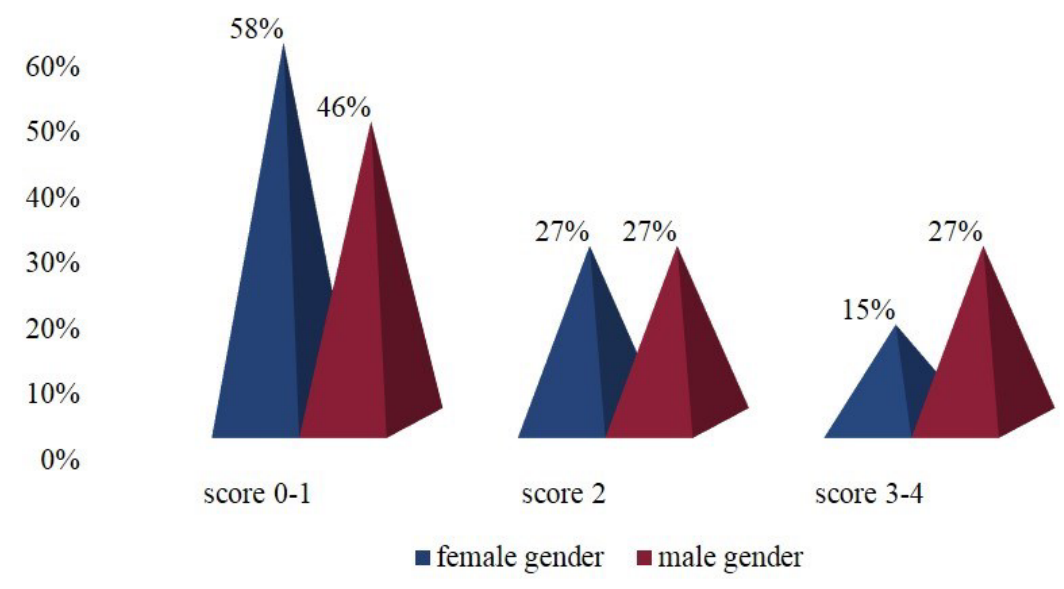

Fig. 3. Imagination vs. Gender

Men have difficulty in operating the imaging constructs against women, by twice the percentage $(27 \%$ vs $15 \%)$.

Some details are captured by people with Asperger obsessively, while others are not noticed at all. 


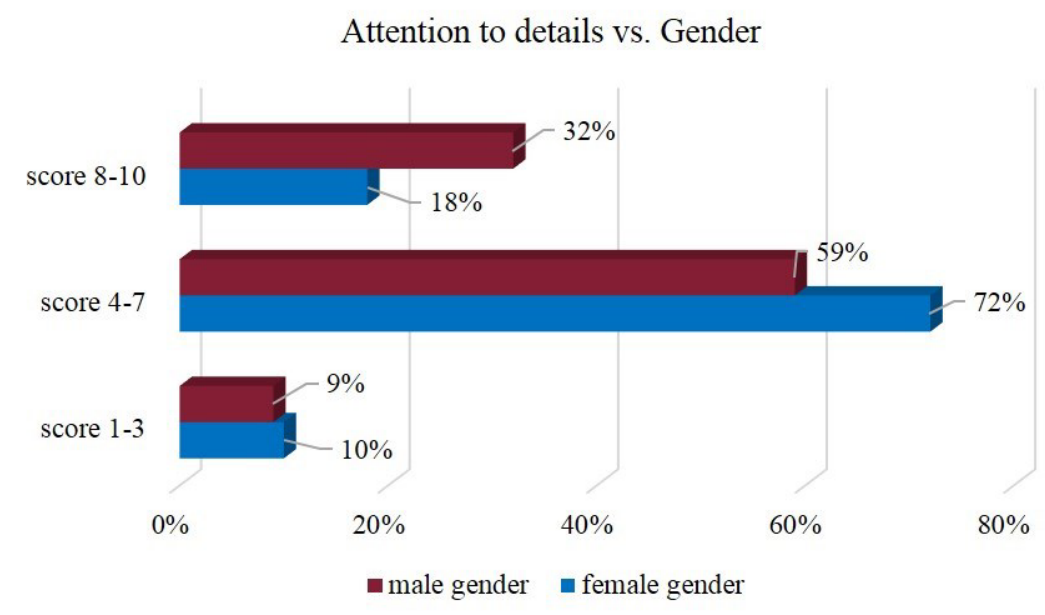

Fig. 4. Attention to details vs. Gender

Men generally given less weight than women to details, scores over 8 specific behavior is an indication of asperger.

People with Asperger become sad or anxious when removed from familiar places or when something changes in their daily routine. People female exhibit lower tolerance to change $71 \%$ compared to men $-52 \%$.

Research conducted at the level of children

Subjects were 45 children aged between 3 and 7 years at a kindergarten in Sibiu. Communication and social skills were tested with Scala A.S.A.S., part of the volume" Asperger's Syndrome: A Guide for Parents and Professionals" by Tony Attwood. Scala as authors and A.J. Attwood M.S. Garnett.

The questionnaire was filled first by parents and then for children with high score, was completed by the teacher also.

Each question or statement has a scale from 1-6, with 1 being the normal level expected of a child 's age at this level.

Following the questionnaire, scores over 22 are those of concern in terms of research. In this percentage falls $6 \%$ of girls and $18 \%$ of boys. In what regards communication skills, a minimum score achieved on this dimension was 6 and the maximum $26.7 \%$ of children had scores extreme, these being girls and boys in equal percentages.

\section{Discussion and conclusions}

$11 \%$ of the questioned population has obtained high scores on the questionnaire AQ, which means that they are facing communication and adaptation difficulties. Comparing with the average obtained in university in the UK, it appears that the population surveyed, the average value of 16 passes around 24. A possible explanation, in my opinion, could be social and cultural values promoted by the history. In Romania, we have " Ewe " as a masterpiece and Romanian shepherd's image as a symbol of freedom, that people have so much confidence in them, they are afraid to have different views. Because of that the scores could be higher. So, communication is a social and cultural component. In Romanian space, communication is conducted harder, there are many barriers, many inhibitions, fears, lack of exercise in expressing their ideas. 
Correlations can be made between data, resulting that adults with communication problems have a better chance to have children who are experiencing the same difficulties. The parents are deeper problems, the more likely their children to inherit.

At the organizational level it is important to objectively identify individual opportunities and develop employees to increase performance. Improving employment inclusion is likely to reduce mental health problems for adults with Asperger syndrome and reduce the burden on those who play a broader supporting role [7].

Like anyone, those with Asperger's can have particular strengths and qualities and it is important to look at some of the attributes which someone with Asperger's brings to the workplace. These can be as follows:

- excellent memory;

- precision and attention to detail;

- mathematical and technical skills;

- a preference for following instructions and abiding by rules;

- sticking to structured programmes;

- direct, open and honest;

- reproduction, imitation and mimicry;

- high level of vocabulary;

- dealing with projects which have a clear beginning, middle and end [8].

\section{References}

1. L.I. Cioca, R.I. Moraru, G.B. Babut, Proceedings of the 15th International Conference The Knowledge-Based Organization, Nicolae Bălcescu Land Forces Academy, Sibiu, Romania, 26-28 November, 2, 43-48 (2009)

2. L.I. Cioca, L. Ivascu, 3rd International Conference on Social Sciences and Society (ICSSS), 27-28 December, 32, 74-79 (2013)

3. L.I. Cioca, L. Ivascu, S. Rus, Proceedings of the 4th Review of Management and Economic Engineering International Management Conference, The Management between Profit and Social Responsibility, 18th - 20th September, Technical University of Cluj-Napoca, Todesco Publishing House, Romania, 2-7 (2014)

4. R. Moraru, G. Babut, L.I. Cioca, Archives of Mining sciences, 55 (4), 873-878 (2010)

5. T. Attwood, Asperger's Syndrome: A Guide For Parents And Professionals (Jessica Kingsley Publishers, London 1998)

6. S. Lesco, Employment and Asperger Syndrom, (Available at: www.autism.com/advocacy_lesco)

7. J. Richards, Personnel Review, 41 (5), 630-646 (2012)

8. M. Matusiak, Is It possible my Colleague Has Asperger's Syndrome?, (Available at: https://livingautism.com/possible-colleague-aspergers-syndrome) 